\title{
Incidence of bradyarrhythmias in hypertensive and chronic kidney disease patients with mild $v$ s. severe obstructive sleep apnea
}

\author{
Márcio Galindo Kiuchi ${ }^{*}$ and Shaojie Chen ${ }^{2}$ \\ ${ }^{1}$ Division of Cardiac Surgery and Artificial Cardiac Stimulation, Department of Medicine, Hospital e Clínica São Gonçalo, São Gonçalo, RJ, Brazil \\ ${ }^{2}$ Department of Cardiology, Shanghai First People's Hospital, Shanghai Jiao Tong University School of Medicine, Shanghai, China
}

Obstructive sleep apnea (OSA) may lead to atrial fibrillation (AF), a common cardiac arrhythmia. Particularly, OSA is a risk factor for stroke and hypertension [1,2]. Further, continuous positive airway pressure (CPAP) reduces death and cardiovascular events and improves hypertension control [3,4]. Accentuated sympathetic nerve activity is a robust risk factor for cardiovascular events, such as cerebral infarction and myocardial infarction [5]. Peripheral sympathetic nerve activity is accentuated in patients with hypertension, congestive heart failure, OSA, obesity, diabetes, and chronic renal illnesses. The obstructive events result in sleep disruption, hypoxemia, and are associated with an increased prevalence of arrhythmias [6].

We aim to compare the incidence of bradyarrhythmic events in CKD and hypertensive patients with mild vs. severe OSA, recorded by the 24-hour-Holter monitoring after OSA degree diagnosed by the polysomnography. This retrospective study involved 182 subjects divided into mild OSA $(n=94)$ and severe OSA $(n=88)$. The study was conducted in accordance with the Helsinki declaration and was approved by the ethics committee of our institution. All patients signed the informed consent before inclusion. Patients were evaluated between January 2013 and January 2016 at the Arrhythmias and Artificial Cardiac Pacing Service at Hospital e Clínica São Gonçalo, Rio de Janeiro, Brazil. Patients who met the following criteria were consecutively enrolled: (i) essential hypertension more than one year; (ii) Mild OSA: 5 to 15 Apnea/Hypopnea index (AHI) events/ hour; (iii) Severe OSA: $>30$ AHI events/hour; (iv) age between 18 and 80 years; (v) structurally normal heart to myocardial scintigraphy, without ischemia or fibrosis area, previously diagnosed, presenting left ventricular ejection fraction measured by Simpson's method $>50 \%$; (vi) glomerular filtration rate estimated by the Chronic Kidney Disease Epidemiology Collaboration (CKD-EPI equation [7], eGFR $>60 \mathrm{~mL} /$ $\mathrm{min} / 1.73 \mathrm{~m}^{2}$ with microalbuminuria or eGFR $<60 \mathrm{~mL} / \mathrm{min} / 1.73 \mathrm{~m}^{2}$ ); and (vii) capacity to read, comprehend, and sign the informed consent form and attend the clinical tests. Patients that presented any of the subsequent criteria were excluded: (i) pregnancy; (ii) valvular disease with significant adverse sequelae; (iii) unstable angina, myocardial infarction, transient ischemic attack or stroke; (iv) renovascular abnormalities; (v) psychiatric disease; (vi) known addiction to drugs or alcohol that affects the intellect; (vii) serious health condition that, in the investigator opinion's, may adversely affect the safety and/or efficacy of the participant or the study; (viii) congestive heart failure of functional class II to IV according to the New York Heart Association. The primary endpoint was to record episodes of bradyarrhythmias registered by the 24-hour-Holter monitoring.
The 24-hour ABPM [8] and polysomnography [9] execution were previously described. The results are expressed as a mean and standard deviation for normally distributed data and as median with interquartile range otherwise. All statistical tests were two-sided. Comparisons between two-paired values were performed with the paired t-test in cases of normally distributed variables, and by the Wilcoxon test in cases of non-normally distributed variables. Comparisons between more than two-paired values were made by repeated-measures analysis of variance or by Kruskal-Wallis analysis of variance as appropriate, complemented by a post-hoc test. Categorical variables were compared with Fisher's exact test. A P-value $<0.05$ was considered significant. Correlations between two variables were performed by Pearson's chisquare test in case of a Gaussian distribution and with the Spearman correlation test otherwise. All statistical analyses were performed using the program Graph pad Prism v 7.0 (Graph pad Software, La Jolla, CA, USA).

The general features of both groups are disposed of in Table 1. Analyzing the events of bradyarrhythmia recorded by the 24-hourHolter monitoring, pauses $>3$ seconds, $2^{\text {nd }}$ degree atrioventricular (AVB) Mobitz I, $2^{\text {nd }}$ degree AVB Mobitz II, and $3^{\text {rd }}$ degree AVB occurrence was much higher in the group with severe OSA $(68.2 \%$, $56.9 \%, 46.8 \%$, and $36.4 \%$, respectively) than in the group presenting mild OSA (11.7\%, 21.3\%, 26.6\%, and $16.0 \%$, respectively), $\mathrm{P}<0.0001$, $\mathrm{P}<0.0001, \mathrm{P}=0.0063$, and $\mathrm{P}=0.0022$, respectively, as shown in (Figure 1). The relative risk for bradyarrhythmic events in hypertensive CKD patients evaluated by Fisher's exact test was presented in Figure 1. Our data showed that in patients with severe OSA, the risk of bradyarrhythmic events occurrence is significantly higher than in patients only with mild OSA.

\section{Conflict of interest}

None declared.

Correspondence to: Márcio Galindo Kiuchi, Division of Cardiac Surgery and Artificial Cardiac Stimulation, Department of Medicine, Hospital e Clínica São Gonçalo Rua Cel. Moreira César, 138- Centro, Rio de Janeiro 24440-400, Brazil, Tel/Fax: +55(21) 26047744; E-mail: marciokiuchi@gmail.com

Received: November 28, 2016; Accepted: December 20, 2016; Published: December 23, 2016 
(A)

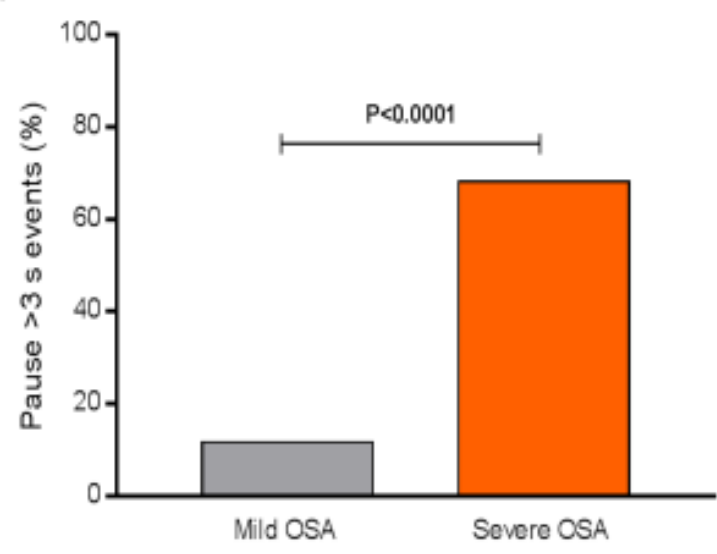

(C)

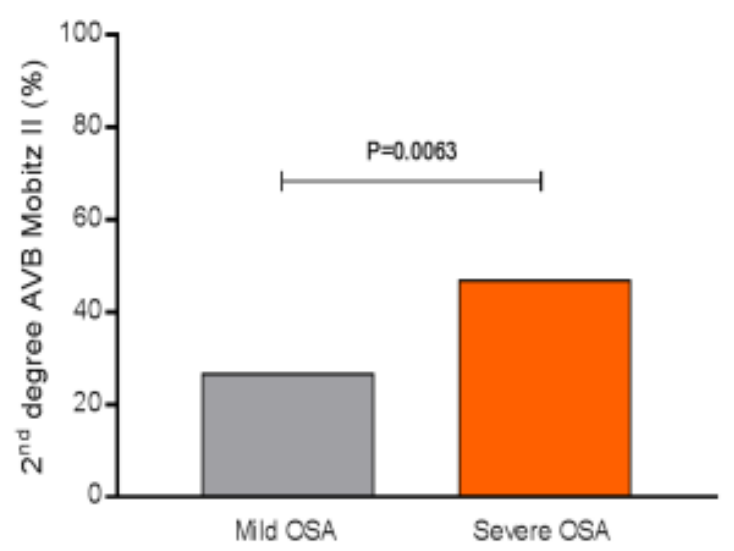

(B)

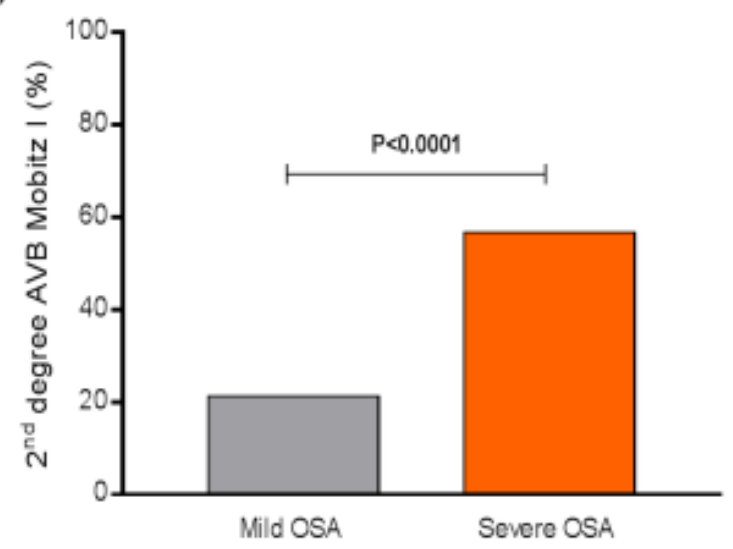

(D)

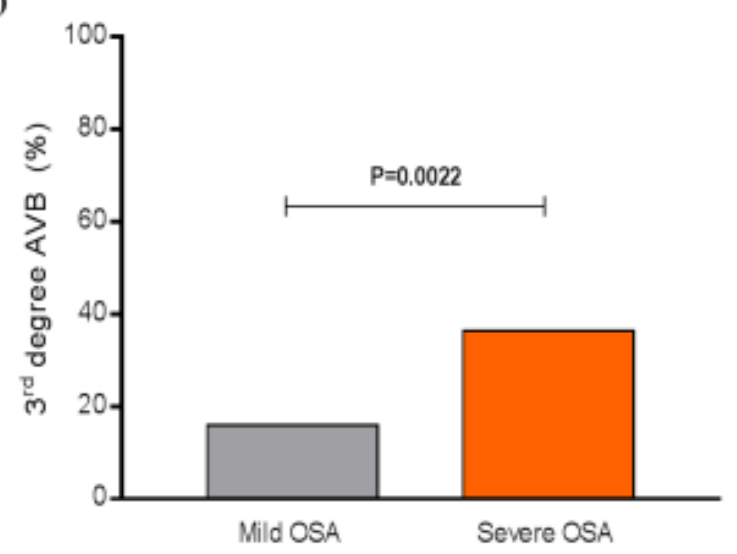

\section{$\underline{\text { Relative risk for bradvarrhythmic events evaluated by Fisher's exact test in CKD patients }}$}

$\begin{array}{cccc}\text { Severe } v s . \text { Mild OSA } & \text { Relative Risk } & 95 \% \text { Confidence Interval } & \text { P value } \\ \text { Pauses }>3 \text { seconds } & 4.826 & 2.876-8.502 & <0.0001 \\ 2^{\text {nd }} \text { degree AVB Mobitz I } & 2.313 & 1.600-3.486 & <0.0001 \\ 2^{\text {nd }} \text { degree AVB Mobitz II } & 1.600 & 1.152-2.305 & 0.0063 \\ 3^{\text {rd }} \text { degree AVB } & 1.834 & 1.227-2.926 & 0.0022\end{array}$

AVB, atrioventricular block; OSA, obstructive sleep apnea

Figure 1. Percentage and Relative Risk of bradyarrhythmias occurrence recorded by the 24-hour-Holter monitoring: (A) pause $>3$ seconds, (B) $2^{\text {nd }}$ degree AVB Mobitz I, (C) $2^{\text {nd }}$ degree AVB Mobitz II, and (D) $3^{\text {rd }}$ degree AVB. AVB, atrioventricular block; OSA, obstructive sleep apnea; Mild OSA, n=94; Severe OSA, n=88.

\section{Funding}

This study was funded by Pacemed (US \$150,000), Rio de Janeiro, Brazil.

\section{Acknowledgements}

The authors are grateful to all study participants. The authors also thank Pacemed for contributing to the development of this study and for providing technical support.. 
Table 1. General features of patients at baseline.

\begin{tabular}{|c|c|c|c|}
\hline & Mild OSA & Severe OSA & Pvalue \\
\hline $\mathrm{N}$ & 94 & 88 & --- \\
\hline Age, years & $58.0 \pm 15.1$ & $62.3 \pm 16.6$ & 0.0689 \\
\hline Body mass index, $\mathrm{kg} / \mathrm{m}^{2}$ & $28.3 \pm 5.5$ & $30.6 \pm 4.8$ & 0.0031 \\
\hline Male sex $(\%)$ & $70(74 \%)$ & $63(72 \%)$ & 0.4495 \\
\hline White ethnicity (\%) & $60(64 \%)$ & $51(58 \%)$ & 0.5378 \\
\hline Type 2 Diabetes Mellitus (\%) & $33(35 \%)$ & $42(45 \%)$ & 0.2334 \\
\hline Coronary artery disease $(\%)$ & $20(21 \%)$ & $28(33 \%)$ & 0.0945 \\
\hline Creatinine, $\mathrm{mg} / \mathrm{dL}$ & $1.60 \pm 0.30$ & $1.53 \pm 0.56$ & 0.2904 \\
\hline eGFR, mL/min/1.73m² (CKD-EPI) & $47.0 \pm 12.1$ & $48.3 \pm 20.5$ & 0.6003 \\
\hline Albumin: creatinine ratio, $\mathrm{mg} / \mathrm{g}$ & $76.5 \pm 19.4$ & $73.0 \pm 10.6$ & 0.1364 \\
\hline Hypertension (\%) & $94(100 \%)$ & $88(100 \%)$ & 1.0000 \\
\hline Mean 24-hour ABPM, mmHg & $137.0 \pm 6.2 / 89.3 \pm 8.5$ & $138.0 \pm 8.8 / 92.7 \pm 7.2$ & $0.3743 / 0.9181$ \\
\hline Apnea/hypopnea index, events/hour & $10.5 \pm 6.4$ & $55.2 \pm 10.1$ & $<0.0001$ \\
\hline \multicolumn{4}{|l|}{ Antihypertensive Agents } \\
\hline ACE inhibitors/ARB & $94(100 \%)$ & $88(100 \%)$ & 1.0000 \\
\hline Diuretics & $70(74 \%)$ & $75(85 \%)$ & 0.0966 \\
\hline $\mathrm{DHP} \mathrm{Ca}^{++}$channel blockers & $94(100 \%)$ & $88(100 \%)$ & 1.0000 \\
\hline
\end{tabular}

Values are presented as Mean \pm SD or \%; ABPM, ambulatory blood pressure measurements; ACE, angiotensin-converting enzyme; ARB, angiotensin receptor blocker; CKD-EPI, Chronic Kidney Disease Epidemiology Collaboration; DHP, dihydropyridine; eGFR, estimated glomerular filtration rate; HR, heart rate; N, number of patients; OSA, obstructive sleep apnea.

\section{References}

1. Chobanian AV, Bakris GL, Black HR, Cushman WC, Green LA, et al. (2003) The seventh report of the joint national committee on prevention, detection, evaluation, and treatment of high blood pressure: the JNC7 report. JAMA 289: 2560-2572. [Crossref]

2. Dong JY, Zhang YH, Qin LQ (2013) Obstructive sleep apnea and cardiovascular risk: meta-analysis of prospective cohort studies. Atherosclerosis 229: 489-495. [Crossref]

3. Drager LF, Bortolotto LA, Figueiredo AC, Krieger EM, Lorenzi GF (2007) Effects of continuous positive airway pressure on early signs of atherosclerosis in obstructive sleep apnea. Am J Respir Crit Care Med 176: 706-712. [Crossref]

4. Litvin AY, Sukmarova ZN, Elfimova EM, Aksenova AV, Galitsin PV, et al. (2013) Effects of CPAP on "vascular" risk factors in patients with obstructive sleep apnea and arterial hypertension. Vasc Health Risk Manag 9: 229-235. [Crossref]
5. Julius S, Jamerson K (1994) Sympathetics, insulin resistance and coronary risk in hypertension: the 'chicken-and-egg' question. J Hypertens 12: 495-502. [Crossref]

6. Esler M, Lambert G, Brunner-La Rocca HP, Vaddadi G, Kaye D. (2003) Sympathetic nerve activity and neurotransmitter release in humans: translation from pathophysiology into clinical practice. Acta Physiol Scand 177: 275-284. [Crossref]

7. Levey AS, Stevens LA, Schmid CH, Zhang YL, Castro AF III, et al. (2009) A new equation to estimate glomerular filtration rate. Ann Intern Med 150: 604-612. [Crossref]

8. Kiuchi MG, E Silva GR, Paz LM, Chen S, Souto GL. (2016) Proof of concept study: renal sympathetic denervation for treatment of polymorphic premature ventricular complexes. J Interv Card Electrophysiol 47(2):221-229. [Crossref]

9. (1999) Sleep-related breathing disorders in adults: recommendations for syndrome definition and measurement techniques in clinical research-the report of an American Academy of Sleep Medicine Task Force. Sleep 22: 667-689. [Crossref]

Copyright: (C2016 Kiuchi MG. This is an open-access article distributed under the terms of the Creative Commons Attribution License, which permits unrestricted use, distribution, and reproduction in any medium, provided the original author and source are credited. 